\title{
Distalização dos molares superiores com aparelho Pendex: estudo em modelos de gesso
}

\author{
Eduardo César Almada Santos*, Omar Gabriel da Silva Filho**, Patrícia Maria Pizzo Reis**, \\ Francisco Antônio Bertoz $z^{\star \star *}$
}

\section{Resumo}

Objetivo: a presente pesquisa clínica, longitudinal e prospectiva, avaliou os efeitos do aparelho Pendex mediante o emprego de modelos de gesso. Metodologia: utilizou-se uma amostra de 30 modelos de gesso, obtidos no início e no final da distalização dos molares superiores com o aparelho Pendex, de 15 jovens brasileiros tratados no Curso de Pós-Graduação, nível de Mestrado em Ortodontia, da Faculdade de Odontologia de Araçatuba - UNESP. Resultados e Conclusões: os resultados mostraram aumento do perímetro do arco dentário superior com inclinação distal e controle transversal dos primeiros molares superiores.

Palavras-chave: Má oclusão Classe II de Angle. Aparelhos ortodônticos. Aparelho Pendex e Pêndulo. Distalização dos molares.

\section{INTRODUÇÃO E REVISÃO DE LITERATURA}

Não deixa de ser provocativa, para os ortodontistas habituados com a ancoragem extrabucal tradicional, a possibilidade de distalizar os molares superiores com a grande diversidade de aparelhos de ancoragem intrabucal e intramaxilar inseridos no arsenal ortodôntico contemporâneo, os chamados distalizadores intrabucais. Esses dispositivos, em evidência a partir da década de 1990, têm o seu mérito na distalização dos molares sem a colaboração do paciente e sem o efeito ortopédico de restrição do deslocamento anterior da maxila, mesmo quando aplicados durante o surto de crescimento da adolescência. Do ponto de vista clínico, esses aparelhos corrigem a Classe II, desencadeando a distalização dos molares, sem necessitarem da cooperação do paciente, e com estimativa de tempo para se alcançar o objetivo. Enfim, os distalizadores intrabucais constituem alternativa viável, na clínica ortodôntica, para distalização dos molares superiores, como esclarece a tabela 1, porém aplicados com ressalvas, ou seja, com uma visão equilibrada dos seus efeitos (Fig. 1).

Os aparelhos Pêndulo e Pendex, idealizados por Hilgers ${ }^{10,12}$, ou quaisquer de suas variações ${ }^{1 \text {, }}$ $2,5,6,7,8,15,16,17,18,19,20,23,24,25,26$ fazem parte dessa gama de aparelhos que induzem efeito dentário, sem influência esquelética e sem exigir cooperação. O presente trabalho de pesquisa fecha a trilogia de estudos empenhados em explicitar os efeitos induzidos a curto prazo pelo aparelho Pendex usando uma amostra prospectiva da disciplina

* Professor Assistente Doutor da Disciplina de Ortodontia do Departamento de Odontologia Infantil e Social da Faculdade de Odontologia de Araçatuba, UNESP.

** Mestrando em Odontologia, Área de Concentração Ortodontia da Faculdade de Odontologia de Araçatuba, UNESP.

*** Professor Titular da Disciplina de Ortodontia do Departamento de Odontologia Infantil e Social da Faculdade de Odontologia de Araçatuba, UNESP. 
Tabela 1 - Compilação da literatura pertinente aos efeitos do aparelho Pêndulo e Pendex.

\begin{tabular}{|c|c|c|c|c|c|c|c|}
\hline \multirow{2}{*}{ Autor } & \multirow{2}{*}{$\mathbf{n}$} & \multirow{2}{*}{ Tempo de tratamento } & \multirow{2}{*}{ Ancoragem } & \multicolumn{2}{|c|}{ Inclinação } & \multirow{2}{*}{ Intervalo ativação } & \multirow{2}{*}{$\begin{array}{l}\text { Velocidade } \\
\text { distalização }\end{array}$} \\
\hline & & & & 6 & 7 & & \\
\hline BURKHARDT et al. ${ }^{3}$ (2003) & 30 & 6,5 meses & Nance & $10^{\circ}$ & - & 3-4 semanas & $0,9 \mathrm{~mm} / \mathrm{mês}$ \\
\hline $\begin{array}{l}\text { BUSSICK; MCNAMARA JR. } \\
(2000)\end{array}$ & 101 & $\begin{array}{l}\text { Até obtenção } \\
\text { relação de Classe I } \\
\text { limite III }\end{array}$ & Nance & $10,6^{\circ}$ & - & 3-4 semanas & $5,7 \mathrm{~mm}$ (total) \\
\hline $\begin{array}{l}\text { BYLOFF; DARENDELILER }{ }^{5} \\
\text { (1997) }\end{array}$ & 13 & 4,15 meses & Nance & $14,5^{\circ}$ & - & $\begin{array}{l}1 \text { ou duas vezes du- } \\
\text { rante o tratamento }\end{array}$ & $0,8 \mathrm{~mm} / \mathrm{mês}$ \\
\hline BYLOFF et al. ${ }^{6}$ (1997) & 20 & 6,8 meses & Nance & $6,1^{\circ}$ & - & Cada 7 dias & $1,2 \mathrm{~mm} / \mathrm{mês}$ \\
\hline $\begin{array}{l}\text { CHAQUÉS-ASENSI; KALRA }{ }^{8} \\
(2001)\end{array}$ & 26 & 6,5 meses & $\begin{array}{l}\text { Botão } \\
\text { palatino }\end{array}$ & $13,1^{\circ}$ & $14,23^{\circ}$ & $\begin{array}{c}\text { Sem ativação durante } \\
\text { tratamento }\end{array}$ & $0,8 \mathrm{~mm} / \mathrm{mês}$ \\
\hline GHOSH; NANDA9 (1996) & 41 & 6,2 meses & $\begin{array}{l}\text { Botão } \\
\text { palatino }\end{array}$ & $8,36^{\circ}$ & $11,99^{\circ}$ & $\begin{array}{l}\text { Sem ativação durante } \\
\text { tratamento }\end{array}$ & $0,5 \mathrm{~mm} / \mathrm{mês}$ \\
\hline JOSEPH; BUTCHART ${ }^{14}(2000)$ & 7 & 3,4 meses & Nance & $15,7^{\circ}$ & - & $\begin{array}{l}\text { Sem ativação durante } \\
\text { tratamento }\end{array}$ & 1,5mm/mês \\
\hline KINZINGER et al. ${ }^{18}$ (2004) & 36 & 5,5 meses & Nance & $3,29^{\circ}$ & $5,49^{\circ}$ & Cada consulta & $0.57 \mathrm{~mm} / \mathrm{mês}$ \\
\hline SANTOS et al. ${ }^{21}$ (no prelo) & 15 & 5 meses & $\begin{array}{l}\text { Expansor } \\
\text { Haas }\end{array}$ & $4,06^{\circ}$ & - & 30 dias & $0,8 \mathrm{~mm} / \mathrm{mês}$ \\
\hline
\end{tabular}

de Ortodontia da Faculdade de Odontologia de Araçatuba - UNESP. As duas empreitadas anteriores basearam-se na cefalometria ${ }^{21}$, que confirmou a ausência de efeitos ortopédicos e reafirmou os efeitos ortodônticos nos molares e na ancoragem, e na radiografia panorâmica ${ }^{22}$,

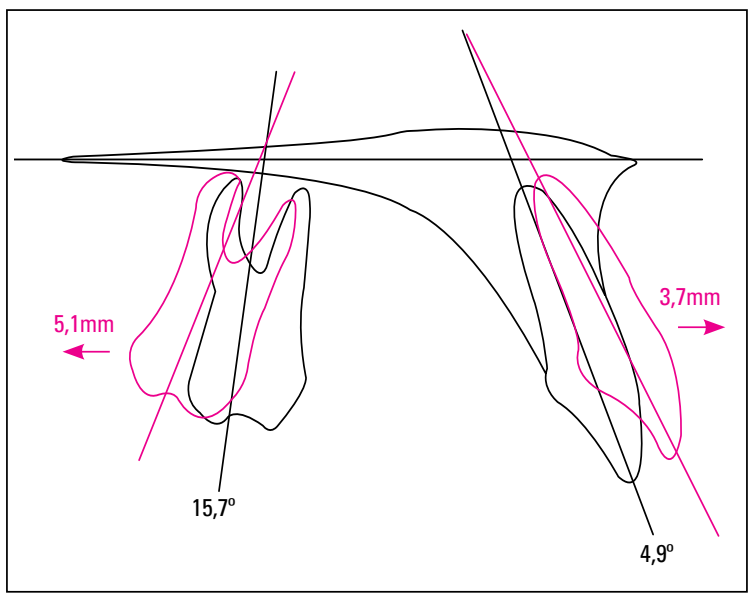

FIGURA 1 - Sobreposição cefalométrica expondo as alterações médias suscitadas pelo aparelho Pêndulo sobre os molares e os incisivos centrais superiores. Obedecendo aos princípios newtonianos, se a ação da mecânica está na distalização dos molares, a reação está na inclinação vestibular dos incisivos. Fonte: Joseph e Butchart ${ }^{14}$ (2000). que confirmou o movimento de inclinação dos primeiros e segundos molares superiores durante a distalização. Na verdade, a coroa do molar se desloca para distal, enquanto a raiz nem sempre. A avaliação mediante emprego da telerradiografia lateral ${ }^{21}$ demonstrou inclinação distal dos molares com uma velocidade média de $0,8 \mathrm{~mm} / \mathrm{mês}$ acompanhada de vestibularização dos incisivos superiores, com aumento do trespasse horizontal. Essa inclinação vestibular dos dentes anteriores se traduz como perda de ancoragem. Num resultado otimista da literatu$\mathrm{ra}^{17}, 72,5 \%$ do espaço aberto com o Pêndulo foi atribuído à distalização dos molares e somente $27,5 \%$ correspondeu à perda de ancoragem, o que se aproxima da perda de ancoragem sugerida pelo criador do aparelho Pêndulo, que é de $20 \%$. A figura 1 retrata com clareza os efeitos provocados pelo aparelho Pêndulo.

O presente trabalho de pesquisa lançou mão de modelos de gesso para avaliar o comportamento sagital, vertical e transversal dos molares superiores decorrente do uso do Pendex. 


\section{MATERIAL E MÉTODO Material}

Para o presente estudo longitudinal e prospectivo, utilizou-se uma amostra de 30 modelos de gesso, obtidos no início e no final da distalização dos molares superiores com o aparelho Pendex, de 15 jovens brasileiros tratados no Curso de PósGraduação, nível de Mestrado em Ortodontia, da Faculdade de Odontologia de Araçatuba - UNESP, por uma única profissional. Todos os pacientes, sendo 9 do gênero masculino e 6 do gênero feminino, apresentavam má oclusão de Classe II, com média de idade de 11 anos e 3 meses, numa faixa etária entre 9 e 15 anos. Não foram incluídos pacientes com agenesias, perda precoce de dentes

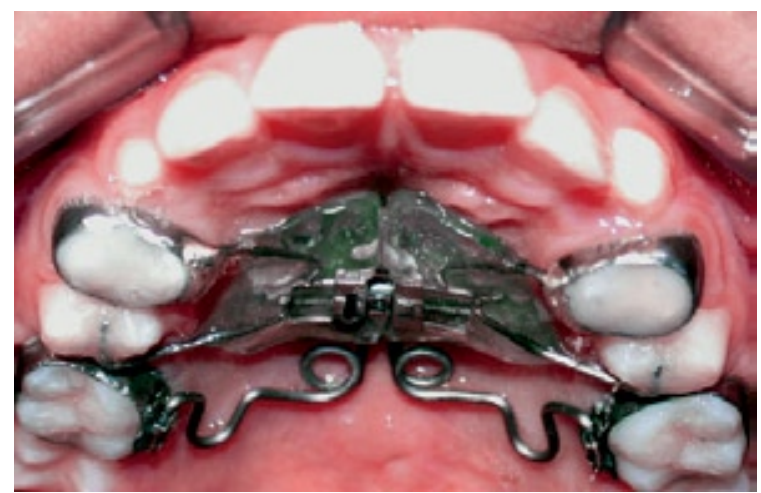

FIGURA 2 - Aparelho distalizador intrabucal Pendex utilizado na presente pesquisa.

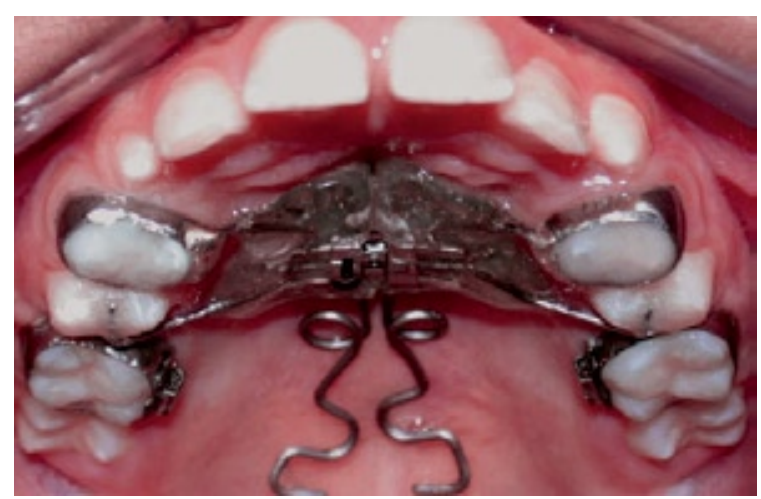

FIGURA 4 - Mola distalizadora de TMA ativada: deve manter-se paralela à rafe palatina mediana. decíduos e pacientes submetidos a qualquer tipo de tratamento ortodôntico prévio.

Para a coleta de dados, o presente estudo foi devidamente aprovado pelo Comitê de Ética em Pesquisa em Humanos da Faculdade de Odontologia de Araçatuba - UNESP.

\section{Método}

Descrição dos passos do tratamento

O aparelho distalizador intrabucal Pendex utilizado no presente trabalho (Fig. 2) constituiu-se de bandas nos primeiros pré-molares e primeiros molares permanentes superiores, apoios oclusais na distal dos segundos pré-molares, parafuso expansor, botões acrílicos e molas distalizadoras

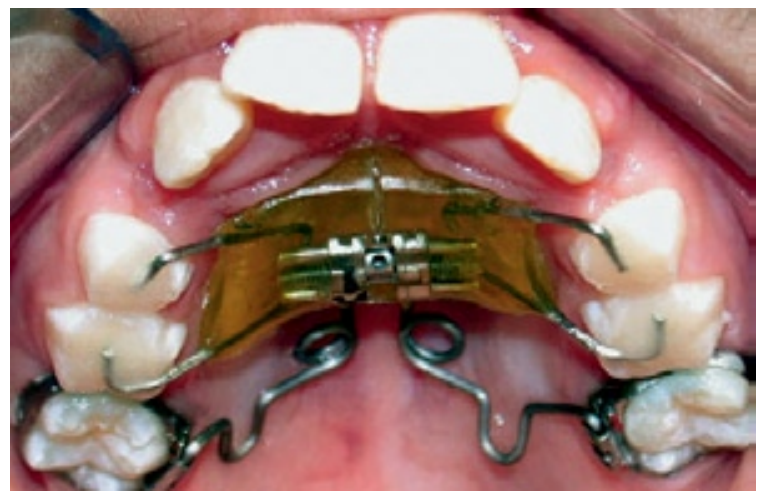

FIGURA 3 - Aparelho distalizador Pendex quando os primeiros pré-molares não haviam irrompido. Note a presença dos apoios oclusais na mesial dos primeiros molares decíduos superiores fixados com resina composta fotopolimerizável.

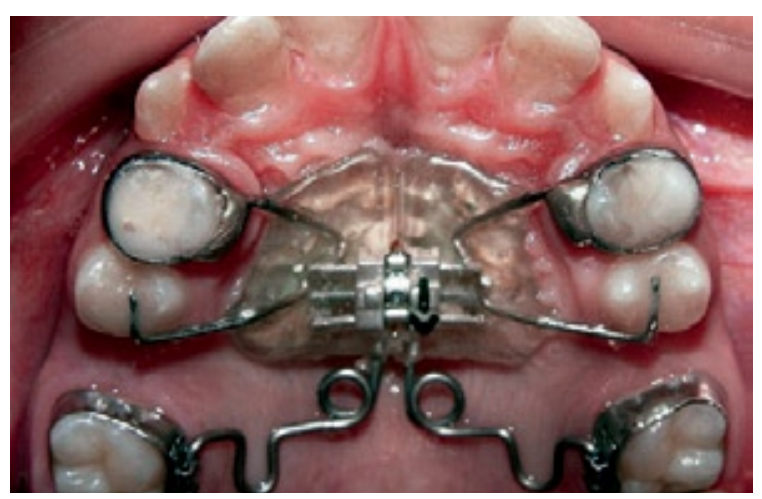

FIGURA 5 - Distalização dos molares permantes com as molas de TMA. 


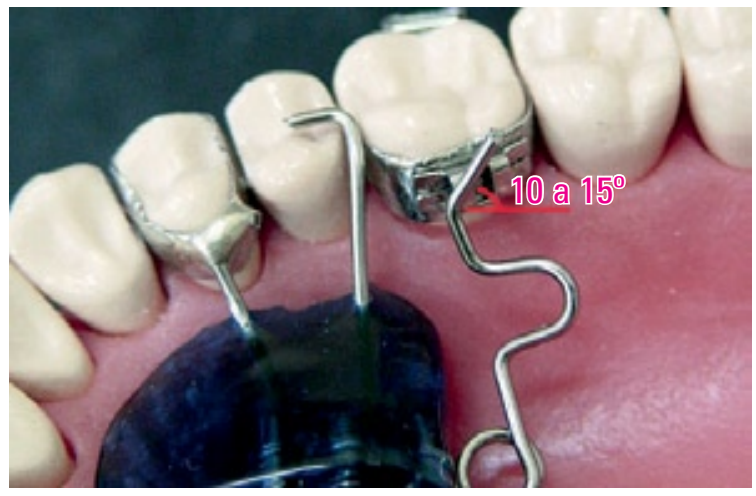

FIGURA 6 - Dobra anti-inclinação de $15^{\circ}$ para oclusal com o intuito de promover a verticalização das raízes do primeiro molar permanente superior após a distalização da coroa.

de TMA (titânio-molibdênio). As bandas foram cimentadas com cimento de ionômero de vidro modificado com resina (Fuji Ortho LC - GC Corporation, Tokyo, Japan - sistema pó-líquido). Dos 15 pacientes apenas um apresentava os primeiros molares decíduos superiores na cavidade bucal. Para este caso, não foi realizada a bandagem dos primeiros molares decíduos e sim a confecção de apoios oclusais na mesial dos respectivos dentes com fio de aço 0,9 mm (Fig. 3). Antes da cimentação do aparelho distalizador, as molas foram ativadas de forma a deixá-las paralelas à rafe palatina mediana (Fig. 4). De acordo com Hilgers e Tracey $^{13}$, cerca de $1 / 3$ desta força é anulada durante o encaixe do segmento intratubo da mola distalizadora no tubo palatino do primeiro molar superior permanente. A força registrada pelo tensiômetro

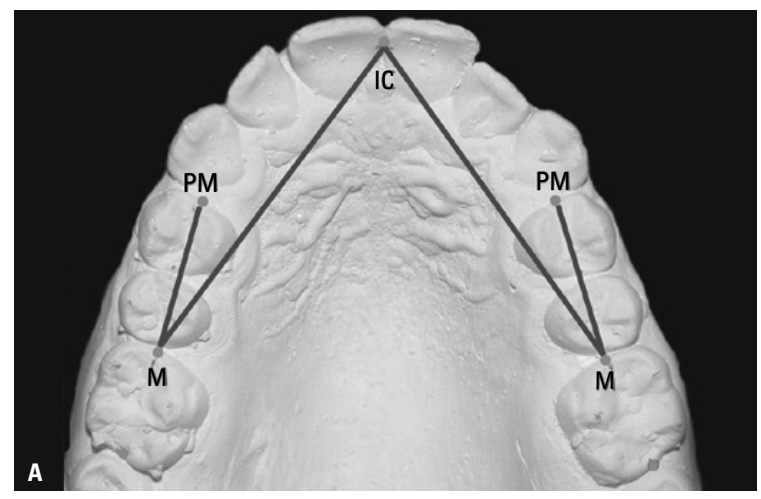

FIGURA 7 - A) Inicial; B) Pós-distalização.
Dontrix (ETM Corporation, Monrovia, Califórnia) foi de aproximadamente 300g por lado. As avaliações foram realizadas quinzenalmente e as ativações das molas a cada trinta dias, conforme a necessidade de correção da relação molar. $\mathrm{O}$ aparelho foi removido quando os primeiros molares encontravam-se sobrecorrigidos e o tempo gasto para alcançar este objetivo durou em média 5,2 meses (Fig. 5). No momento em que se observou a cúspide mésio-vestibular do primeiro molar superior ocluindo com o sulco mésio-vestibular do primeiro molar inferior, foi realizada uma dobra anti-inclinação no segmento intratubo da mola distalizadora com $15^{\circ}$ de inclinação para oclusal (Fig. 6). O objetivo desta dobra era promover a verticalização da raiz, conferindo à distalização do primeiro molar superior permanente um movimento próximo ao de corpo, conforme proposto por Byloff e Darendeliler ${ }^{5}$.

Descrição da metodologia sobre os modelos de gesso

Os modelos de gesso do arco dentário superior inicial e pós-distalização foram usados para avaliar o efeito produzido pelo aparelho Pendex. O comportamento sagital do arco dentário superior foi avaliado por duas grandezas (Fig. 7), uma representativa do segmento posterior e outra do comprimento total do arco superior. A grandeza do segmento posterior estende-se da crista

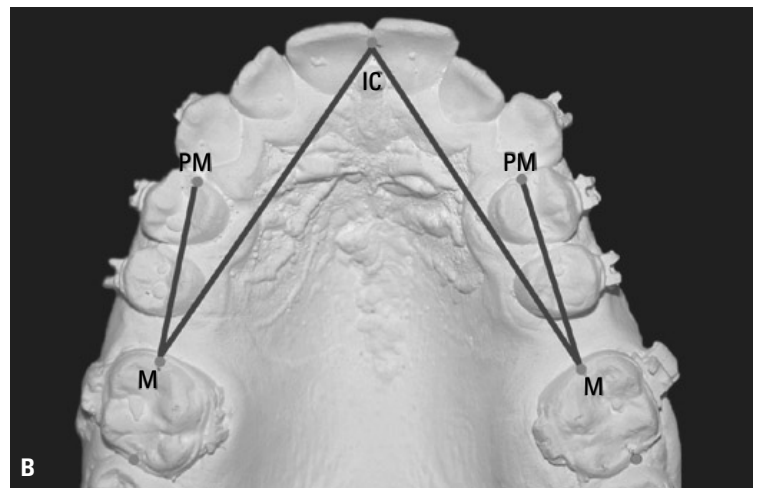



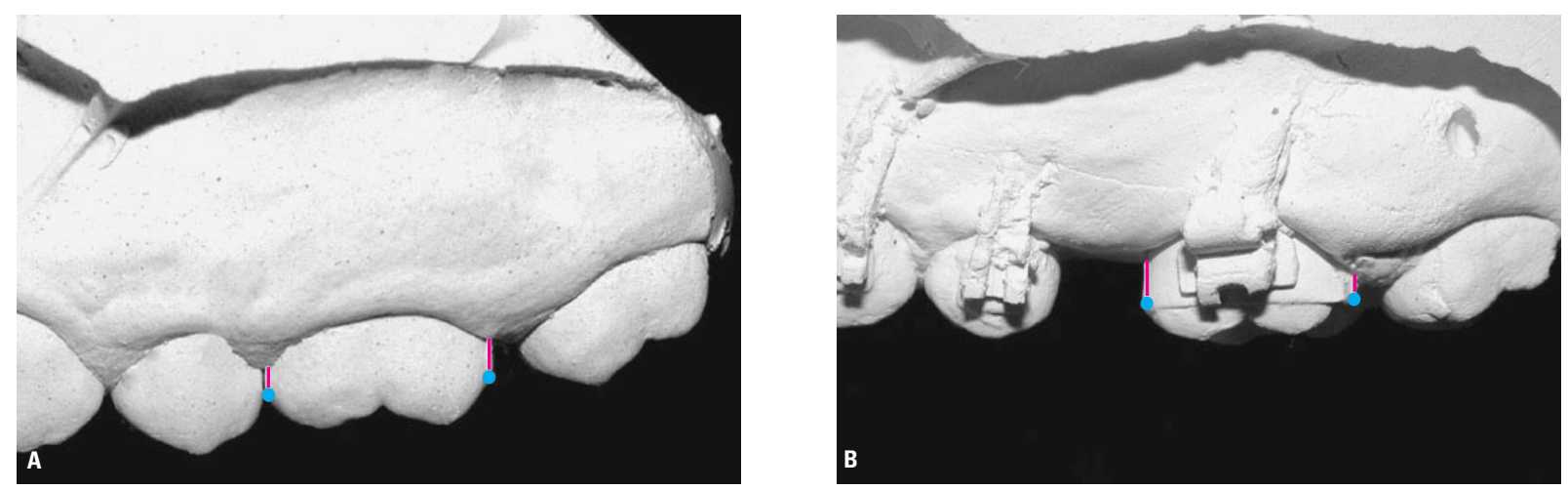

FIGURA 8 - A) Inicial; B) Pós-distalização - Grandezas verticais: comprimento das ameias vestibulares, mesial e distal.
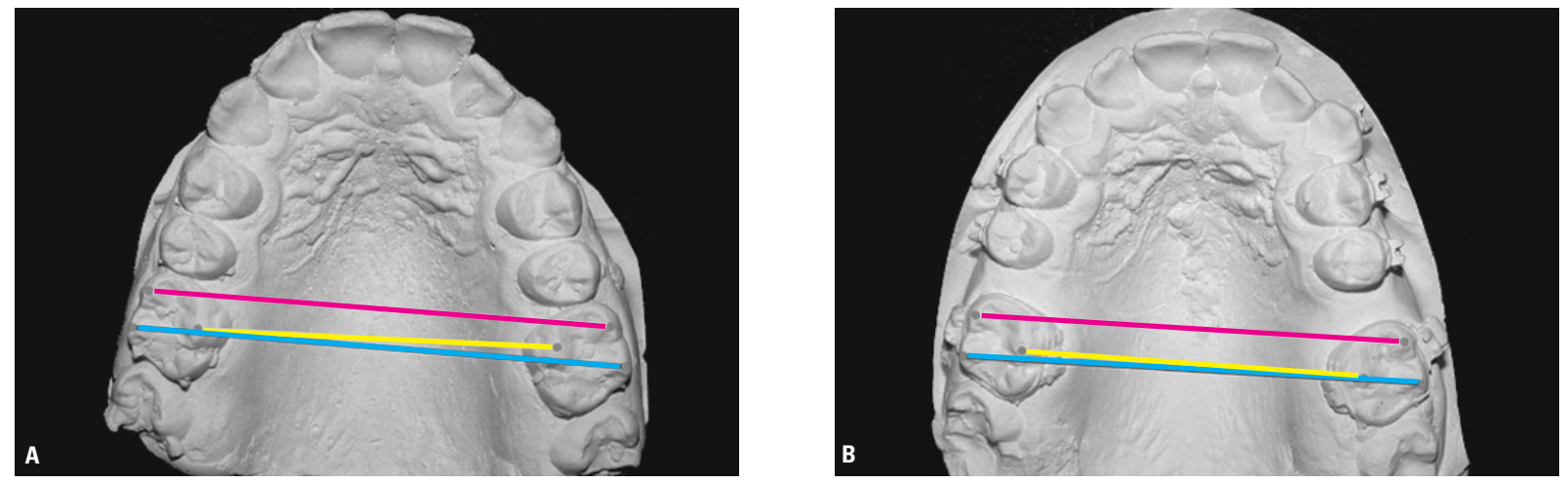

FIGURA 9 - A) Inicial; B) Pós-distalização - Grandezas transversais: MV-MV, DV-DV, MP-MP.

marginal mesial do primeiro molar superior até a crista marginal mesial do primeiro pré-molar, dos dois lados. São nomeados M-PMD e M-PME, onde as últimas letras identificam os lados direito (D) e esquerdo (E). A grandeza do comprimento total do arco estende-se da crista marginal mesial do primeiro molar superior até a borda mesial do incisivo central do lado correspondente. Essas grandezas receberam a identificação de M-ICD e M-ICE.

O comportamento vertical do primeiro molar foi avaliado na superfície vestibular, mediante comprimento da coroa nas ameias interproximais mesial e distal (Fig. 8). Essas grandezas receberam os nomes Ameia mesial D, Ameia mesial E, Ameia distal D e Ameia distal D, em ambos os lados nos modelos, inicial e pós-distalização.

O comportamento transversal do arco den- tário superior foi avaliado pela distância entre as cúspides mésio-vestibulares, as cúspides disto-vestibulares e as cúspides mésio-palatinas (Fig. 9). Essas três medidas são identificadas como MV-MV, DV-DV e MP-MP.

\section{RESULTADOS E DISCUSSÃO}

A distalização dos molares superiores passa a ser uma exigência do tratamento quando a intenção é corrigir a relação de Classe II sem extração de dentes e sem avanço mandibular. Além de influenciar a relação inter-arcos, a distalização dos molares reflete na relação intra-arco, com aumento do perímetro do arco dentário superior, o que pode ser revertido na correção do apinhamento superior e/ou na correção do trespasse horizontal aumentado. Ao contrário dos aparelhos fixos, o AEB depende integralmente da cooperação do paciente 
Tabela 2 - Média e desvio-padrão das medidas pré e pósdistalização dos molares. Aplicação do teste tentre as medidas pré e pós-distalização.

\begin{tabular}{cccccc}
\hline \multirow{2}{*}{ MEDIDAS SAGITAIS } & \multicolumn{2}{c}{ Inicial } & \multicolumn{2}{c}{ Final } & Teste t \\
\cline { 2 - 6 } M-ICD & $\mathbf{X}$ & $\mathbf{D P}$ & $\mathbf{X}$ & $\mathbf{D P}$ & \\
\cline { 2 - 6 } M-ICE & $36,86 \mathrm{~mm}$ & 2,30 & $42,64 \mathrm{~mm}$ & 2,16 & 0,00000 \\
M-PMD & $36,43 \mathrm{~mm}$ & 3,04 & $42,50 \mathrm{~mm}$ & 3,06 & 0,00000 \\
M-PME & $15,61 \mathrm{~mm}$ & 1,47 & $22,77 \mathrm{~mm}$ & 2,34 & 0,00000 \\
MEDIDAS VERTICAIS & $15,21 \mathrm{~mm}$ & 2,33 & $23,14 \mathrm{~mm}$ & 2,63 & 0,00000 \\
AMEIA MESIAL D & $1,93 \mathrm{~mm}$ & 0,51 & $4,11 \mathrm{~mm}$ & 0,63 & 0,00000 \\
AMEIA DISTAL D & $1,31 \mathrm{~mm}$ & 0,88 & $0,80 \mathrm{~mm}$ & 0,89 & 0,19000 \\
AMEIA MESIAL E & $1,89 \mathrm{~mm}$ & 0,63 & $4,00 \mathrm{~mm}$ & 0,65 & 0,00000 \\
AMEIA DISTAL E & $1,39 \mathrm{~mm}$ & 0,79 & $0,54 \mathrm{~mm}$ & 0,81 & 0,01000 \\
MEDIDAS TRANSVERSAIS & & & & \\
MV-MV & $5,21 \mathrm{~mm}$ & 0,27 & $5,53 \mathrm{~mm}$ & 0,33 & 0,00027 \\
DV-DV & $5,54 \mathrm{~mm}$ & 0,26 & $5,76 \mathrm{~mm}$ & 0,38 & 0,00842 \\
MP-MP & $4,11 \mathrm{~mm}$ & 0,20 & $4,38 \mathrm{~mm}$ & 0,36 & 0,00255 \\
\hline
\end{tabular}

no que tange ao número de horas de uso diário, o que muitas vezes o torna pródigo em "metas não cumpridas". Em vista dessa vicissitude, a distalização dos molares superiores exclusivamente com o AEB representa visão superada pelas evidências acadêmicas e clínicas (Tab. 1): os distalizadores intrabucais, fixos, constituem dispositivos imersos na prática ortodôntica contemporânea.

A presente pesquisa usou modelos de gesso para avaliar os efeitos do aparelho Pendex aplicado no final da dentadura mista ou na dentadura permanente. $\mathrm{O}$ aparelho Pendex, assim como o seu original Pêndulo, foram idealizados por Hilgers ${ }^{10,11,12} \mathrm{e}$ Hilgers e Tracey ${ }^{13}$ e têm sido divulgados na literatura desde o início da década de 1990, acrescido de muitas variações. Sua característica principal que o diferencia dos demais distalizadores é ter como elemento ativo para distalização dos molares uma mola confeccionada de TMA (liga titânio-molibdênio) de 0,032" de diâmetro, a qual é inserida no tubo palatino dos primeiros e ou segundos molares superiores com intenção de movimentá-los para distal seguindo uma curvatura pendular, o que ori- ginou o seu nome. Este efeito pendular da mola distalizadora provoca a movimentação do molar para palatino, com rotação e inclinação distal. Quanto à ativação, Hilgers ${ }^{12}$ recomendou deixar a mola distalizadora paralela à rafe palatina a fim de liberar uma força contínua com magnitude entre 200 e 300 gramas de cada lado, com o intuito de distalizar até $5 \mathrm{~mm}$ num período de tempo de 3 a 4 meses, admitindo que $20 \%$ desse espaço deve-se à perda de ancoragem anterior (Fig. 1).

A comparação dos modelos de gesso pré e pósdistalização dos molares superiores (Fig. 7) revelou a criação de espaço na mesial dos primeiros molares. É inegável, portanto, o aumento do perímetro do arco dentário superior. Os números das medidas sagitais mostram isso na tabela 2. A distância dos molares aos incisivos aumentou $6 \mathrm{~mm}$ enquanto a distância dos molares aos primeiros pré-molares aumentou $7 \mathrm{~mm}$ com o efeito do Pendex. O espaço criado é maior do que o encontrado na literatura em modelos de gesso, cujos valores para o espaço aberto na mesial do 16 e do 26 foram, respectivamente, $4,6 \mathrm{~mm}$ e $4,4 \mathrm{~mm}^{17}$.

As medidas sagitais da tabela 2 mostraram que houve ganho de espaço no arco dentário superior, mas não determinaram o quanto esse ganho é real, ou seja, qual porcentagem desse espaço representava distalização dos molares e qual porcentagem correspondia à mesialização dos pré-molares, acompanhada ou não de vestibularização dos incisivos. A literatura tem divulgado uma distalização média dos primeiros molares superiores variável, de $3,37 \mathrm{~mm}^{9}, 3,39 \mathrm{~mm}^{5}, 4,14 \mathrm{~mm}^{6}, 5,7 \mathrm{~mm}^{4}$, $5,1 \mathrm{~mm}^{14}$ e $5,9 \mathrm{~mm}^{3}$. Outrossim, a literatura tem mostrado a mesialização dos pré-molares ${ }^{4,5,9}$, com movimento de inclinação ${ }^{9}$, e a vestibularização dos incisivos superiores ${ }^{3,4,5,21}$. A perda de ancoragem significa que a ancoragem utilizada no aparelho, um apoio de acrílico encostado na mucosa palatina, não conseguiu neutralizar a reação do aparelho distalizador. De fato, esse aspecto mecânico, ação e reação dentro da boca, é uma de suas desvantagens em relação ao AEB. A prodigiosa trans- 

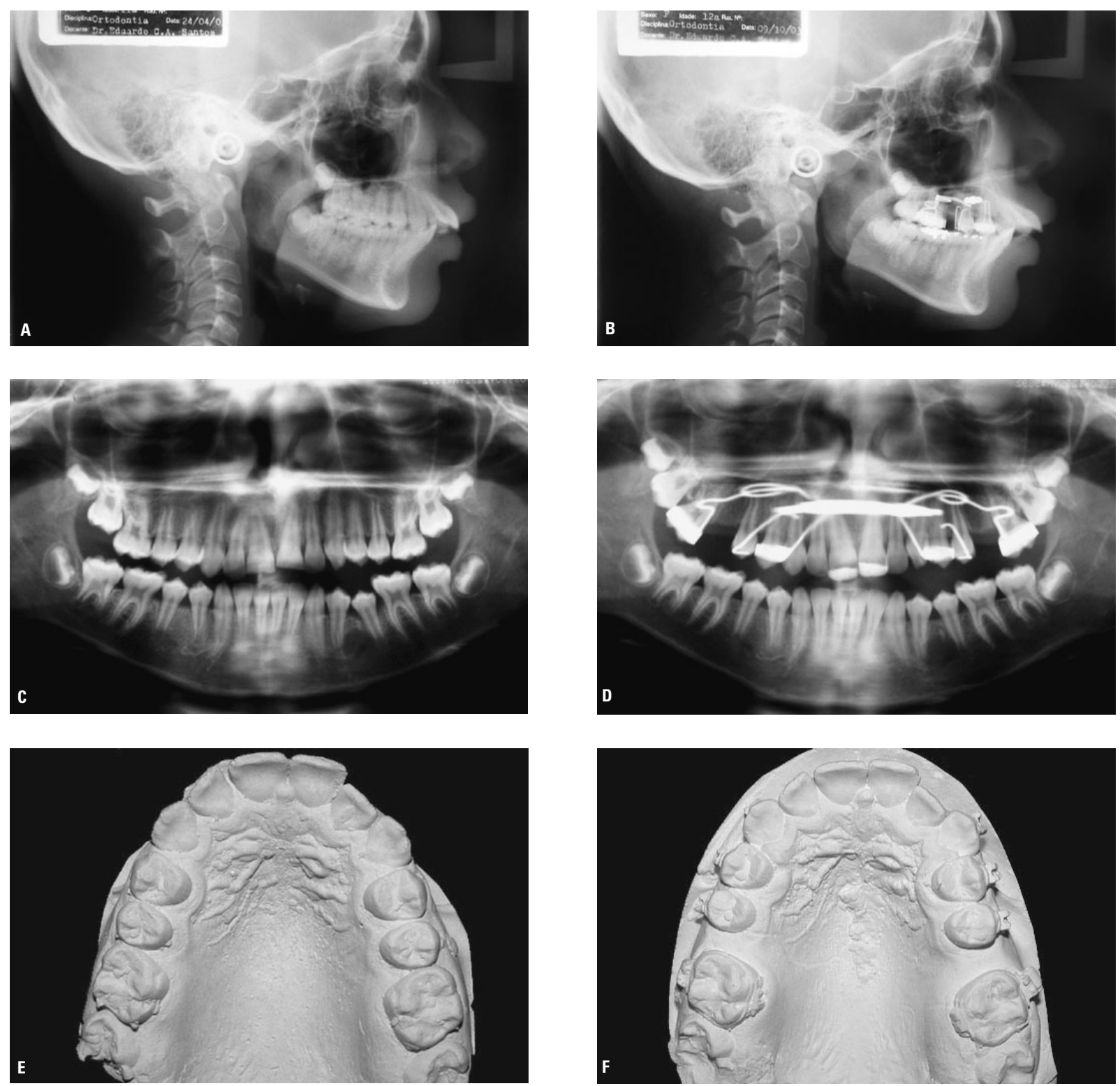

FIGURA 10 - Comportamento dos molares frente à distalização com aparelho Pendex: telerradiografia lateral, radiografia panorâmica e modelos.

formação que os mini-parafusos para ancoragem ortodôntica vem induzindo na clínica ortodôntica promete anular a reação dos distalizadores intrabucais e com isso eliminar um de seus grandes inconvenientes: a perda de ancoragem.

Se o espaço aberto na mesial dos primeiros molares determina aumento do perímetro do arco superior, é preciso igualmente reconhecer um fato inquietante, do ponto de vista prático: os molares inclinam para distal. Em trabalho com radiografia panorâmica ${ }^{22}$ quantificou-se em $19^{\circ}$ e $22^{\circ}$ a inclinação distal dos primeiros molares, fato este já repetido com telerradiografia lateral: $8,369^{\circ}$, $10,64^{\circ}, 14,55^{\circ}, 15,714^{\circ}$ e $3,14^{\circ}$. Encontrou-se, inclusive, correlação significante entre a quantidade de distalização e o grau de inclinação distal dos molares ${ }^{5}$. Essa constatação prévia em metodologia cefalométrica é substanciada no presente trabalho 
mediante o comportamento das medidas verticais realizadas nas ameias mesial e distal dos molares, antes e depois da distalização dos molares (Fig. 8). A altura da ameia mesial aumentou cerca de $2 \mathrm{~mm}$, sugerindo extrusão, enquanto a altura da ameia distal reduziu cerca de $1 \mathrm{~mm}$, sugerindo intrusão (Tab. 2). A extrusão da ameia mesial e a intrusão da ameia distal refletem o movimento de inclinação dos molares para distal. Por isso, podemos dizer que os molares distalizam inclinando, concordando com Kinzinger et al. ${ }^{17}$ em pesquisa realizada com modelos de gesso.

Em síntese, os modelos comprovam que os molares superiores são inclinados para distal, abrindo espaço à frente dos primeiros molares, com o uso do aparelho Pendex. A inclinação dos molares superiores para distal com o uso do Pendex foi confirmada nos três estudos que compõem a trilogia de Araçatuba: telerradiografia lateral ${ }^{21}$, radiografia panorâmica $^{22}$ e, no presente artigo, modelos de gesso (Fig. 10). A implicação disso volta-se principalmente para a estabilidade pós-tratamento comprometida, com relato na literatura de até quase 90\% de recidiva da distalização dos molares ${ }^{3}$.

A inclinação distal dos molares durante sua distalização é previsivelmente extensível a todos os distalizadores intrabucais, não se restringindo ao efeito do aparelho Pendex. Este representa o elemento-chave na resposta a esta abordagem mecânica: distalização com aparelhos intrabucais. A explicação mecânica para a inclinação está na localização do ponto de aplicação da força em relação ao centro de resistência do molar e na impossibilidade em fazer com que a linha de ação de força passe pelo centro de resistência. Essa inclinação para distal não desqualifica o resultado, mas impõe limites na quantidade de distalização possível durante o planejamento ortodôntico, bem como exige providências durante a execução da distalização, como: o uso de dobra anti-inclinação, sobrecorreção e a estabilização do molar distalizado depois da suspensão do aparelho distalizador. As dobras compensatórias nas molas distaliza- doras não cumprem em toda plenitude a função anunciada de distalizar a raiz dos molares distalizados $^{5,21,22}$, pelo menos de um modo geral.

Byloff et $a 1 .{ }^{6}$ tentaram corrigir a inclinação distal dos molares superiores incorporando uma dobra de contra-angulação com a intenção de inclinar a raiz dos molares para distal. Conseguiram atenuar a inclinação, sem no entanto alcançar um movimento de corpo. Santos et al. ${ }^{22}$, trabalhando com radiografia panorâmica e com telerradiografia lateral $^{21,22}$, também não conseguiram distalizar a raiz dos molares na mesma proporção que a coroa, mesmo com a dobra anti-inclinação sendo aplicada aos molares, após o restabelecimento da relação molar de Classe I.

O terceiro grupo de medidas, as transversais (Tab. 2), avalia o comportamento do molar no sentido vestíbulo-lingual mediante 3 grandezas (Fig. 9): distância entre as cúspides mésio-vestibulares, distância entre as cúspides disto-vestibulares e distância entre as cúspides mésio-palatinas dos primeiros molares. Essas distâncias aumentaram quase na mesma magnitude, entre $2 \mathrm{~mm}$ e $3 \mathrm{~mm}$, o que depreende que não houve rotação e tão pouco movimento importante dos molares no sentido transversal. O desenho da mola distalizadora de TMA confere inúmeras habilidades: distalização da coroa, inclinação distal da raiz e vestibularização dos molares. Essa última permite o controle transversal durante a distalização. No presente trabalho, o controle transversal dos molares pode ser obtido pelo aparelho expansor (ativação do parafuso expansor) e pela alça incorporada na mola distalizadora de TMA. O desenho do aparelho Pendex não incluiu os primeiros molares na barra de conexão, como se vê nas figuras 2 a 5, o que significa que o controle transversal ficou em grande parte por conta das molas distalizadoras. Esse ajuste transversal é importante para evitar a mordida cruzada entre os molares durante a distalização dos mesmos.

O trabalho de Kinzinger et al. ${ }^{17}$ demonstrou $1,68 \mathrm{~mm}$ de aumento da distância entre as cúspi- 

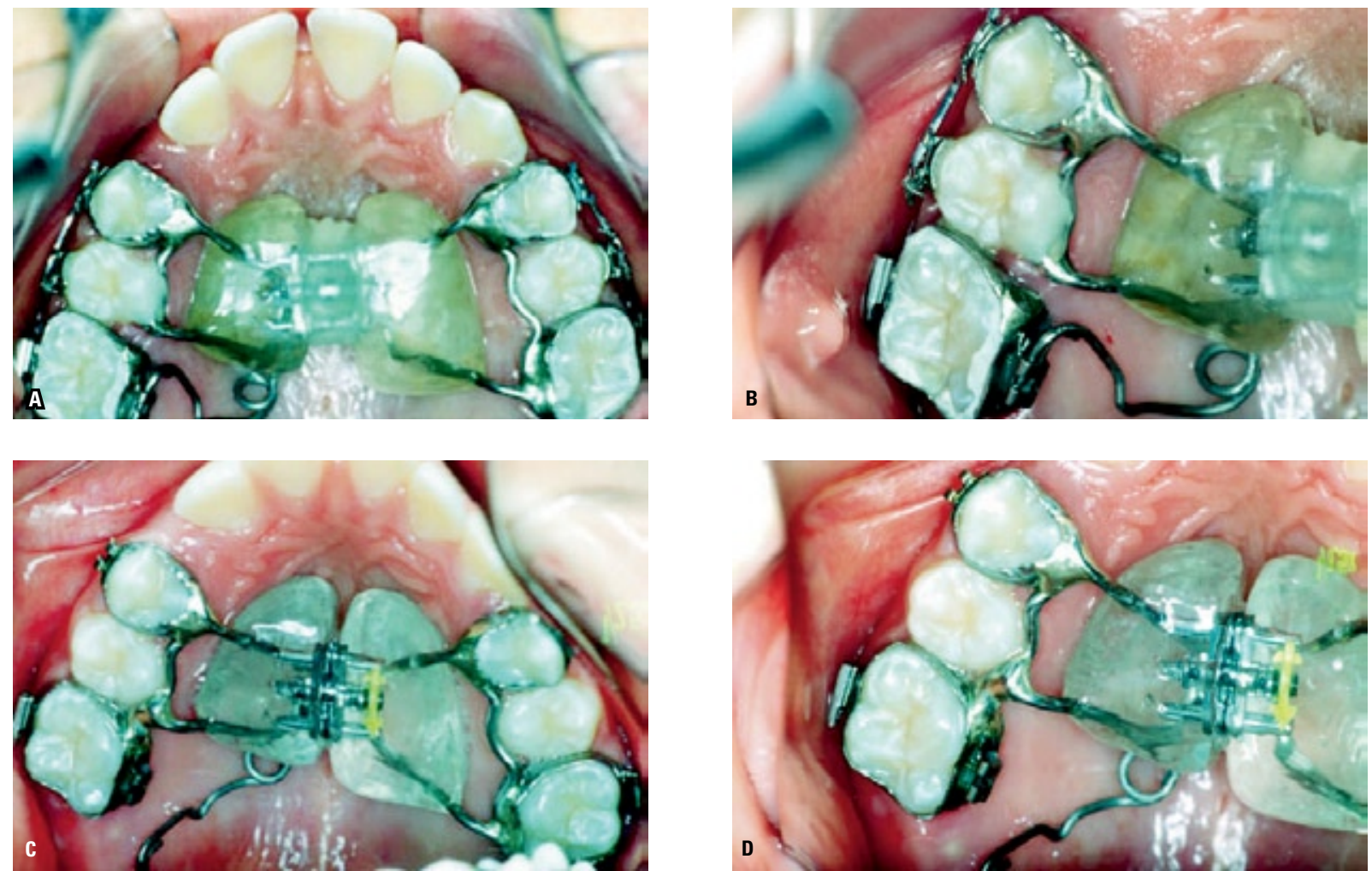

FIGURA 11 - Aparelho Pendex com indicação para dupla mecânica: transversal e sagital. A particularidade deste Pendex reside na soldagem da banda do molar na barra de conexão do aparelho expansor. Num primeiro momento o molar participa da expansão transversal (A, B). Depois das ativações do aparelho expansor, o molar é liberado da barra de conexão, e passa a ser distalizado na mecânica sagital (C, D).

des mésio-vestibulares e $0,96 \mathrm{~mm}$ para a distância entre as cúspides disto-vestibulares, com a ressalva que o movimento transversal foi controlado exclusivamente pelas alças das molas distalizadoras, pois não houve expansão transversal incluída na mecânica de distalização.

Uma sugestão de caráter prático, na mecânica de distalização com o Pendex, é a fixação das bandas dos molares nas barras de conexão do aparelho expansor. Essa conexão transmite aos molares o efeito transversal total atribuído às ativações do parafuso expansor. Finalizada a fase ativa da expansão, os molares que serão distalizados sob o efeito da mola distalizadora devem ser desconectados da barra de conexão, como ilustra a figura 11. Assim se obtém a soma dos efeitos transversal e sagital - vertentes terapêuticas presentes no aparelho Pendex.

\section{CONCLUSÃO}

As medidas realizadas nos modelos de gesso inicial e pós-distalização, com a utilização do aparelho Pendex, permitem observar que é possível aumentar o perímetro do arco dentário superior, em parte pelo menos com a inclinação dos primeiros molares para distal. O movimento dos primeiros molares não é de corpo, como sugere a extrusão da superfície mesial e intrusão da superfície distal dos mesmos. A avaliação transversal mostra discreta vestibularização dos molares. 


\title{
Distal movement of the upper molars with the Pendex appliance: a study with cast models
}

\begin{abstract}
Aim: this clinical longitudinal prospective study evaluated in cast models the effects of the Pendex appliance. Methods: thirty cast models of 15 adolescents treated at the Post-graduate course of the School of Dentistry of Araçatuba - UNESP were obtained at the beginning and at the end of the distal movement of the upper molars with the Pendex appliance. Results and Conclusions: the results showed increase of the upper dental arch perimeter with distal inclination and transverse control of the upper first molars
\end{abstract}

Key words: Class II malocclusion. Pendex appliance. Pendulum appliance. Distal molar movement.

\section{REFERÊNCIAS}

1. ALMEIDA, R. R. et al. Modificação do aparelho Pendulum/ Pend-X: descrição do aparelho e técnica de construção. Rev Dental Press Ortodon Ortop Facial, Maringá, v. 4, n. 6, p. 12-19, nov./dez. 1999 .

2. BORTOLOZO, M. A. et al. Distalização de molares superiores com o Pêndulum/Pendex: o aparelho, seu modo de ação, possibilidades e limitações. Rev Dental Press Ortodon Ortop Facial, Maringá, v. 6, n. 4, p. 43-50, jul./ago. 2001.

3. BURKHARDT, D. R.; MCNAMARA JR., J. A.; BACCETTI, T. Maxillary molar distalization or mandibular enhancement: a cephalometric comparison of comprehensive orthodontic treatment including the pendulum and the Herbst appliances. Am J Orthod Dentofacial Orthop, St. Louis, v. 123, no. 2, p. 108-116, feb. 2003.

4. BUSSICK, T. J.; McNAMARA JR., J. A. Dentoalveolar and skeletal changes associated with the pendulum appliance. Am J Orthod Dentofacial Orthop, St. Louis, v. 117, no. 3, p. 333-343, mar. 2000.

5. BYLOFF, F. K.; DARENDELILER, M. A. Distal molar movement using the pendulum appliance. Part 1: clinical and radiological evaluation. Angle Orthod, Appleton, v. 67, no. 4, p. 249-260, 1997.

6. BYLOFF, F. K. et al. Distal molar movement using the pendulum appliance. Part 2: the effects of maxillary molar root uprighting bends. Angle Orthod, Appleton, v. 67, no. 4, p. 261-270, 1997.

7. BYLOFF, F. K. et al. An implant to eliminate anchorage loss during molar distalization: a case report involving the Graz implantsupported pendulum. Int J Adult Orthodon Orthognath Surg, Chicago, v. 15, no. 2, p. 129-137, summer 2000.

8. CHAQUÉS-ASENSI, J.; KALRA, V. Effects of the pendulum appliance on the dentofacial complex. J Clin Orthod, Boulder, v. 35, no. 4, p. 254-257, apr. 2001.

9. GHOSH, J.; NANDA, R. S. Evaluation of an intraoral maxillary molar distalization technique. Am J Orthod Dentofacial Orthop, St. Louis, v. 110, no. 6, p. 639-646, dec. 1996.

10. HILGERS, J. J. A palatal expansion appliance for non-compliance therapy. J Clin Orthod, Boulder, v. 25, no. 8, p. 491-497, aug. 1991.

11. HILGERS, J. J. Hyperefficient orthodontic treatment using tandem mechanics. Semin Orthod, Philadelphia, v. 4, no. 1, p. 17-25, mar. 1998.

12. HILGERS, J. J. The pendulum appliance for Class II noncompliance therapy. J Clin Orthod, Boulder, v. 26, no. 11, p. 706-714, nov. 1992.

13. HILGERS, J. J.; TRACEY, S. G. The mini-distalizing appliance: the third dimension in maxillary expansion. J Clin Orthod, Boulder, v. 37, no. 9, p. 467-475, sept. 2003.
14. JOSEPH, A. A.; BUTCHART, C. J. An evaluation on the pendulum "distalizing" appliance. Semin Orthod, Philadelphia, v. 6, no. 2, p. 129-135, june 2000.

15. KINZINGER, G.; FRITZ, U.; DIEDRICH, P. R. Bipendulum and quad pendulum for non-compliance molar distalization in adult patients. J Orofac Orthop, Munchen, v. 63, no. 2, p. 154-162, mar. 2002.

16. KINZINGER, G. et al. Efficiency of a pendulum appliance for molar distalization related to second and third molar eruption stage. Am J Orthod Dentofacial Orthop, St. Louis, v. 125, no. 1, p. 8-23, jan. 2004.

17. KINZINGER, G. et al. Modified pendulum appliance including distal screw and uprighting activation for non-compliance therapy of Class II malocclusion in children and adolescents. J Orofac Orthop, Munchen, v. 61, no. 3, p. 175-190, 2000.

18. KINZINGER, G. et al. Molar distalization with different pendulum appliances: in vitro registration of orthodontic forces and moments in the initial phase. J Orofac Orthop, Munchen, v. 65, no. 5, p. 389-409, sept. 2004.

19. MACEDO, D. M.; AIDAR, L. A. A. Dispositivos intrabucais fixos para correção da relação molar de Classe II. Rev Dental Press Ortodon Ortop Facial, Maringá, v. 8, n. 2, p. 63-72, mar./abr. 2003.

20. MACEDO, D. M.; AIDAR, L. A. A. Uso do pêndulo de Hilgers: apresentação de um caso clínico. Rev Dental Press Ortodon Ortop Facial, Maringá, v. 6, n. 1, p. 63-71, jan./fev. 2001.

21. SANTOS, E. C. A. et al. Distalização dos molares superiores com aparelho Pendex: estudo cefalométrico prospectivo. Rev Dental Press Ortodon Ortop Facial (no prelo).

22. SANTOS, E. C. A. et al. Distalização dos molares superiores com aparelho pendex: avaliação mediante radiografia panorâmica. J Bras Ortodon Ortop Facial (no prelo).

23. SCUZZO, G.; PISANI, F.; TAKEMOTO, K. Maxillary molar distalization with a modified pendulum appliance. J Clin Orthod, Boulder, v. 33, no. 11, p. 645-650, nov. 1999.

24. SCUZZO, G. et al. The modified pendulum appliance with removable arms. J Clin Orthod, Boulder, v. 34, no. 4, p. 244-246, apr. 2000.

25. SNODGRASS, D. J. A fixed appliance for maxillary expansion, molar rotation and molar distalization. J Clin Orthod, Boulder, v. 30, no. 3, p.156-159, mar. 1996.

26. URSI, W.; ALMEIDA, G. A. Cooperação mínima utilizando o pêndulo de Hilgers. Rev Dental Press Ortodon Ortop Facial, Maringá, v. 7, n. 2, p. 87-123, mar./abr. 2002.

\footnotetext{
Endereço de correspondência

Eduardo César Almada Santos

Rua José Bonifácio, 1193

CEP: 16015-050 - Araçatuba/SP

almada@foa.unesp.br
} 